\title{
Engaging experience: mobilising personal encounters with mental ill-health in social science
}

\author{
Tineke Broer ${ }^{1} \cdot$ Amy Chandler ${ }^{2}$
}

Published online: 21 February 2019

(c) Springer Nature Limited 2019

In 'Bipolar Expeditions', anthropologist Martin (2009) writes about her experiences of living under the description of manic depression (or bipolar disorder), in the context of a broader ethnography of bipolar disorder. Interspersing her observations of support groups, and other places where such people come together, with her own accounts, Martin's aim is "to explore the daily experiences of those who, for better or worse, are participating in the world that psychopharmacology has opened up" (p. xiii). Pragmatically, her own diagnosis and use of psychotropic drugs gave her access to support groups that she could participate in and observe. Martin reflects briefly on the (methodological) challenges of using her own experiences: "My own condition might provide a route for me to study aspects of mental illness that could not be witnessed in any other way. But fears around the stigma of mental illness would prevent me from using key tools in the craft of ethnography" (p. xii). However, this tantalising glimpse opens up further queries as to the processes and effects entailed of living such a topic of study, where this topic is itself stigmatised, and has historically prompted questions about the reliability of those with such experiences.

Moves such as Martin's, which incorporate personal experience into accounts of research may be paralleled with autoethnography, an increasingly established methodological approach where authors draw directly on their own experiences to analyse or reflect upon broader issues of concern, including topics relating to mental illness. Authors in this tradition have accounted for their drawing on personal experiences in various ways. For instance, Brooks (2011) wrote about "an urgent personal and intellectual need to analyze and share my experience with OCD [Obsessive Compulsive Disorder]" (Brooks 2011, p. 250). Jago (2002) wrote of a similar type of urgency in seeking to tell "a story of the ways in which the realities of academia

Tineke Broer

t.broer_1@uvt.nl

Amy Chandler

a.chandler@ed.ac.uk

1 Tilburg Institute for Law, Technology, and Society, Tilburg Law School, Tilburg University, Tilburg, Netherlands

2 School of Health in Social Science, University of Edinburgh, Edinburgh, UK 
and depression are inextricably bound together in my lived experience" (Jago 2002, p. 733). Thus, these authors-and others-express an (intellectual) desire to 'do' something politically with their own experiences. Both Jago and Brooks write about the consequences of 'coming out', as Brooks calls it, including the potential ramifications for their careers; they also both discuss the consequences for others implicated in their story. Moreover, Brooks discusses how autoethnographic writing, and the vulnerability required, does not automatically serve a purpose; rather, it needs to be useful for the particular text, and, arguing with Behar (1996), "has to take us somewhere we couldn't otherwise get to" (cited in Brooks 2011 p. 250). However, neither Jago nor Brooks addresses the potential epistemological disadvantages of such an autoethnographic project, or the wider (political, academic) consequencesexcept for arguing that coming out may help challenge the stigma around mental illness.

The practice of academics drawing on their own experiences in scholarly texts, however, is far from uncontested. Indeed, one of the more well-rehearsed objections to auto-ethnography is that it constitutes a form of 'navelgazing' (Drechsler Sharp et al. 2012; Humphreys 2005). Moreover, referring to authors such as Martin (and thus not concerned with auto-ethnography as such), French sociologist Alain Ehrenberg (2009) argues that 'admitting' one's mental ill-health in a public place relies on and constructs a particular notion of the self: one that confesses its disturbances in order to promote a social cause. He furthermore connects this to a particularly American way of viewing the self, and argues this ('coming out') is something which French scholars would be far less likely to do, relating this to political and organisational differences between American and French societies. His arguments, though, prompt further reflection on the kinds of subjects we become, enable, or propose, through our knowledge practices, the choices we may make regarding the enrolment of personal experience, and how each of these is shaped by the cultural contexts we inhabit. As such, Ehrenberg's writing leads us to reflect critically on how to-and whether we must - take on certain subject positions (e.g. as 'having depression', 'coming out', being a 'service-user'), and what effects each of these positions may have on our writing and research.

Our aim, as editors of this special issue, is not to take a predefined position for or against the use of personal experiences. Instead, we want to move the debate beyond a for-and-against using personal experiences, towards a consideration of what kind of personhood is implied in the use of personal experiences of ill-health in social research. Indeed, drawing on scholars such as Rose (1998) and Ehrenberg (2009), we investigate the ways in which personal experiences of mental ill-health-in particular-might prompt new ways of thinking about, judging and acting upon the self-with the self being decidedly political. Further, we suggest there is a need for much closer consideration of the philosophical and methodological implications of (not) drawing on such experiences in our research as social scientists, beyond the issue of stigma around mental illness. Resulting from a symposium on the role of personal experiences in social scientific research on mental ill-health that we organised in June 2016, in this special issue we raise questions such as: what kind of self is constructed in choosing (not) to use personal experience in a particular way? What consequences might these choices have? What are the implications for knowledge 
production? What, if anything, is special about (non)disclosure of experiences of mental ill-health, compared to other aspects of biography and selfhood? How, if at all, do personal experiences of mental ill-health or distress enable critical reflection on the conceptualisation of mental health and illness in contemporary medical sociology — as well as in society writ large? What is made in/visible through the use of personal experience in academic writing?

In order to make a start addressing these questions, we invited contributions from a range of disciplines (history, psychology, sociology, service-user research), resulting in a deliberately heterogeneous collection of papers which adopt a range of perspectives and (writing) practices. What they have in common is their focus on mental ill-health research, in particular, and a keen interest in the personal and political more generally. They differ, however, in their take on the debate on personal experiences, and the questions that guide their specific contribution to the special issue. They range from reflections on the consequences of using personal experiences in the act of doing so, through to a critical discussion on how we got to a place where we can think about using personal experiences (and what experience comes to mean in such a context).

While we do not necessarily contend that there is, a priori, anything special about mental ill-health in terms of using personal experiences, arguably mental ill-health research has a relatively longstanding tradition in which the personal, advocacy, and research are combined. Drawing on feminist scholarship among others, mental health service-user/survivor-led research and the standpoint epistemologies central to such endeavours have gained prominence over the past few decades, in part stemming from criticisms regarding unequal relationships between psychiatrists and patients (Beresford 2005; Rose 2017). Such research takes seriously the notion that personal experiences have key consequences for knowledge production and conceptualisations of expertise. This research also has consequences for the selfhood invested in and produced through these studies; researchers actively construct themselves as people with personal experiences of mental ill-health and thereby emphasise this aspect of themselves. Identity politics, then, is a strong feature of this type of research, with researchers positioning their own experiences, diagnoses and emotions in certain ways in order to establish certain effects (e.g. promoting a social cause) (cf. Rose et al. 2004).

Aptly, then, the first paper in this special issue is by Diana Rose, one of the first survivor researchers in the UK, who reflects on the ways in which survivor research has changed over the years. Her paper explores the origins both of her activism and the user movement, and the interrelations between the two, though she also suggests that it is impossible to get to the real origins: this is "but a credible version". Written partly while being in a mental health crisis house, this piece reflects on the credibility and functions of memory, both in the construction of identity and, again relatedly, how to do (user) research. Central questions revolve around the relationship between academia and spaces/knowledge outside academia, how to best access and articulate users' voices, and the politics of personal experience in general. Rose's account is frank, and she reflects candidly on how well "we respond (...) to the kind of madness that is hard to empathise with even whilst I think that having been both high and suicidal I can understand better than most professionals what a person is 
experiencing". Her profoundly personal reflection is simultaneously a suggestion for future research and politics, in which the voice of service users/madness should remain central.

A more recent development and intervention is the field of Mad Studies, that draws significantly on Queer Studies in its positions and theories. The second article in the special issue, by Brigit McWade, reflects on this field, and more broadly on how we come to be positioned as (not) having personal experience, and thus what personal experience means in the context of mental ill-health research. Such positioning, she argues, relies on strict dichotomies: one is either mad or not, either a researcher or a service user. In this paper, then, McWade critically questions these dichotomies, by examining reactions to her doctoral research in which she participated in a mental health service 'as if' she was a service user. She revisits three moments during and after her $\mathrm{PhD}$ where she felt her identity was questioned, and her (embodied) reactions to such questions: during a meeting with the ethics committee; during her viva; and during the organising of a Mad studies conference. In each of these settings, her position (and concordant ethics of her position) were questioned, asking McWade to position herself, whereas, she argues, her "research has always been about how to speak madness against or outside of psy discourse". Drawing on literature on auto-ethnography, anthropology, and mad studies, McWade explores the power relations in identity politics, while also reflecting on her own "white and middle-class" position. She concludes in the spirit in which she started, discussing the "paradoxical rich-ness of (...) knowledge-making: let us all avoid the compulsion to resolve it".

The emphasis on personal experience, then, can divide, categorising people as either mad or not, either a researcher or a survivor. In the third contribution to the special issue, Isabel Frey uses her own experience of bulimia to reflect on, and contribute to, a shared subjectivity. She writes about using her own experiences with bulimia in a qualitative interview study with people who have (had) bulimia, ultimately leading to "a partial account of what it means to try to know bulimia as a former bulimic". While the use of personal experiences in interviews has been both recommended as well as cautioned against (in part on ethical grounds) (Duncombe and Jessop 2002; McKinzie 2017), Frey does not engage in this debate herself, although she argues that it was a "necessity" for her to include her own experiences. Rather, she examines the knowledge practices resulting from a juxtaposition and sharing of different experiences with and subjectivities of bulimia, which she describes as being embodied and affective. In her conclusion, she reflects on what is gained through this sharing of subjectivities, which is, as she argues, "an extended illness narrative that is embodied, situated and shared". This paper then contributes to reflections on what it means to (openly or covertly) use personal experiences when doing research, what is gained and, perhaps, what is lost through doing so (although the paper is less vocal on the potential losses), and to what understandings of mental illness subjectivities this may lead.

In the next set of articles, authors reflect on some of the ideals that are often implicated when scholars draw on their own experiences, or argue why these should, or shouldn't, be used in academic texts. Sarah Chaney's paper is a reflection on the notion of 'objectivity' in historical research. She starts with an illuminating account 
of the discipline of history and the place of objectivity herein, and shows how the style of writing is often as important as the research topic or methodology for establishing objectivity. However, she critically questions the desirability and the possibility of objectivity in history, arguing that it its not only impossible to be fully objective, but also that it leads to better historical research (and thus a clearer view on the present) when historians are aware of and acknowledge their own assumptions and potential biases. This leads her to question the identity of the historian, and to what extent the person is related to, and should be explicitly related to, the research. As a historian researching self-harm, she has often received questions about how she came to study this topic, and what her personal relation was to self-harm. Yet the opposite happened too, that people questioned the legitimacy of her research because of the apparent lack of personal relationship to the topic. Chaney takes up the question of identity politics, and what it means to claim one is, for instance, a 'self-harmer', or that one has experience of self-harming, and what the consequences might be of such claims (thus taking issue with the same dichotomous way of thinking that McWade has addressed as well). She concludes this section with the statement: "As long as we critique them, then, identity categories may be useful just as exploring out own experiences as researchers may be valuable". Throughout, however, she remains agnostic as to the benefits of necessarily claiming an identity as a researcher-and instead argues for reflexivity on the part of all historians.

Simon Clarke and Colin Wright's paper is a theoretical contribution to the debate on the usefulness of using first-person accounts in or as research. They argue that much auto-ethnographic writing, if not all, starts from the notion of authenticity, and claiming a true or real account of 'madness'. However, they argue that there are many problems attached to the notion of authenticity in general and in relation to madness particularly, among which is the heterogeneous nature of madness. While Spivak's suggestion that essentialised notions such as 'women' may be used strategically, she herself, and the authors of the paper, come to the conclusion that such strategic use can still contribute to "the very essentialist tendencies she was seeking to avoid in the first place". Instead, Clarke and Wright argue, with De Certeau, for tactical, rather than strategic, interventions, where, for instance, service users can contribute to the space that psychiatry usually holds, much like "occupations are an important tactic among activists". In this way, the authors argue for "tactical authenticity', which, they argue, "makes it possible to give voice to the radical heterogeneity and singularity of the experience of madness", and as such intervenes in psychiatric hegemonic discourses. Tactics, then, can be seen as a subversive move, "by displacing the identity-categories that we believe are part of the problem".

The final two papers in this volume take a further step back, situating the developments around personal experience in broader practices of knowledge production, without necessarily discussing the impact of their personal experience on the resulting practices of knowledge production. Chris Millard's paper provides a genealogy of how we have come to a place where we can use personal experience in our research. He helpfully suggests that 'experience' is mobilised in specific ways, and not everything that could be is actually seen as experience: "only certain kinds of things are habitually mobilized under that particular banner". Tracing back from academic work that draws on personal experience, Millard outlines 
three developments that have contributed to the conditions of possibility for such use of, and for what comes to be seen as, personal experience: psychoanalysis, social history, and anthropology. He shows how and in what ways experience became an important concept in each of these disciplines. After this helpful genealogy, he reflects on the consequences of the use of personal experience in research. While he argues that it is courageous and "an act of inclusion" to "mak(e) personal experience part of academic accounts, he also argues, with Butler, Scott and Shortall, that doing so "leaves something out"- - suggesting that we can never talk about experience, and give an account of ourself, outside of conventional ways of thinking. As such, it can contribute to essentialising differences, "as much as it seemingly liberates".

David Pilgrim, finally, takes up the question of reductionism, a style of thinking that he argues can be present both in accounts that privilege personal experience as well as in neuroscientific thinking, where personal experience is more usually absent. Arguing that human agency fundamentally stems from open-ended systems, he suggests that any account that wants to generalise and give a causative explanation of all behaviour is reductionistic. Drawing on critical realism as a philosophical tool, he tries to reconcile the two ends of the spectrum (neuroscience and personal experience). While the biopsychosocial model in this respect can be a helpful intervention, he also claims that it is often still used in a reductionistic, biology-centric way, and, as such, "lack(ing) social and political 'outsight"”. Instead, he argues with some neuroscientists that "the brain affords our capacity to be human agents but our conduct cannot be reduced to one or more brain mechanisms". Moreover, he warns us that "our personal accounts are neither a full window into the society we are embedded in, nor into the bodily reality that shapes and constrains our humanity, experience, morbidity and mortality. However, they are important reflexive testimonies about that complexity. They are part of the picture that should neither be sacralised nor scorned".

Taken together, the contributions to this special issue provide a critical, in-depth and varied exploration of the many questions raised and-potentially-answered by engaging with personal experiences in mental health research. What the authors have in common is an awareness that there is no one true account, and they all write within, or despite, this assumption. However, while for some the consequences of drawing on personal experiences as social scientists can best be explored through actually drawing on them, others take a step back and reflect on the history of objectivity in research or offer a genealogy of how we got to a place where this can be a question. Articles range from personal reflections through to theoretical explorations, with some giving concrete suggestions (such as seeing (autoethnographic) writing as a 'tactical intervention') and other articles merely suggesting there is a need for critical (and multiple, open-ended) reflection. Ultimately, we see this collection of papers as a starting point in what we hope will be an ongoing, critical, reflection on the role of personal experiences in mental health research.

Funding Funded by the Foundation for the Sociology of Health and Illness, the grant holders were Tineke Broer, Amy Chandler and Martyn Pickersgill. 


\section{References}

Beresford, P. 2005. Developing the theoretical basis for service user/survivor-led research and equal involvement in research. Epidemiology and Psychiatric Sciences 14 (1): 4-9.

Brooks, C.F. 2011. Social performance and secret ritual: Battling against obsessive-compulsive disorder. Qualitative Health Research 21 (2): 249-261.

Drechsler Sharp, M., J.-L. Riera, and S.R. Jones. 2012. Telling our stories: Using autoethnography to construct identities at the intersections. Journal of Student Affairs Research and Practice 49 (3): $315-332$.

Duncombe, J., and J. Jessop. 2002. Doing Rapport' and the Ethics of 'faking Friendship. In Ethics in qualitative research, ed. M. Mauthner, M. Birch, J. Jessop, and M. Miller, 107-122. London: Sage.

Ehrenberg, A. 2009. Weariness of the Self: Diagnosing the History of Depression in the Contemporary Age. Quebec City: McGill-Queen's Press.

Humphreys, M. 2005. Getting personal: Reflexivity and autoethnographic vignettes. Qualitative inquiry 11 (6): 840-860.

Jago, B.J. 2002. Chronicling an academic depression. Journal of contemporary ethnography 31 (6): $729-757$.

Martin, E. 2009. Bipolar expeditions: Mania and depression in American culture. Princeton, NJ: Princeton University Press.

McKinzie, A.E. 2017. Scared to Death: Reflections on Panic and Anxiety in the Field. Symbolic Interaction 40 (4): 483-497.

Rose, D. 2017. Service user/survivor-led research in mental health: Epistemological possibilities. Disability and Society 32 (6): 773-789.

Rose, D., P. Fleischmann, T. Wykes, M. Leese, and J. Bindman. 2004. Consumers' views of electroconvulsive therapy: A qualitative analysis. Journal of Mental Health 13 (3): 285-293.

Rose, N. 1998. Inventing Ourselves: Psychology, Power, and Personhood. Cambridge: Cambridge University Press.

Publisher's Note Springer Nature remains neutral with regard to jurisdictional claims in published maps and institutional affiliations.

Tineke Broer is Assistant Professor at the Tilburg Institute for Law, Technology and Society, Tilburg Law School, Tilburg University, with research interests in the sociology of emerging (diagnostic) technologies and how these affect the domain of mental health.

Amy Chandler is Chancellor's Fellow in the School of Health in Social Science. Her research draws on sociological perspectives on health and bodies to explore experiences and understandings of self-harm, suicide and drug use. Her monograph, Self-injury, Medicine and Society: Authentic Bodies (2016) drew primarily on empirical research with people who self-injured, but incorporated critical reflections on the role her own experience with self-injury played in the research process. 